\title{
Fat-Storing Multilocular Cells Expressing CCR5 Increase in the Thymus with Advancing Age: Potential Role for CCR5 Ligands on the Difierentiation and Migration of Preadipocytes
}

\author{
Valeria de Mello Coelho ${ }^{1,4}$, Allyson Bunbury¹, Leticia B. Rangel2 ${ }^{2}$ Banabihari Giri', Ashani Weeraratna ${ }^{1}$, \\ Patrice J. Morin ${ }^{2}$, Michel Bernier ${ }^{3}$ and Dennis D. Taub ${ }^{1 凶}$ \\ 1. Laboratories of Immunology, National Institute on Aging, National Institutes of Health, Baltimore, MD, USA; \\ 2. Cellular and Molecular Biology, National Institute on Aging, National Institutes of Health, Baltimore, MD, USA; \\ 3. Clinical Investigation, National Institute on Aging, National Institutes of Health, Baltimore, MD, USA; \\ 4. Institute of Biomedical Sciences, Federal University of Rio de Janeiro, RJ, Brazil
}

$\triangle$ Correspondence to: Dennis D. Taub, PhD, Laboratory of Immunology, Clinical Immunology Section, National Institute on Aging-Intramural Research Program, NIH, Biomedical Research Center, 251 Bayview Blvd, Room 8C222, Baltimore, MD. 21224, USA. Phone: 410-558-8181; Fax: 410-558-8284; E-mail: TaubD@grc.nia.nih.gov

Received: 2009.11.17; Accepted: 2009.12.03; Published: 2009.12.04

\begin{abstract}
Age-associated thymic involution is characterized by decreased thymopoiesis, adipocyte deposition and changes in the expression of various thymic microenvironmental factors. In this work, we characterized the distribution of fat-storing cells within the aging thymus. We found an increase of unilocular adipocytes, ERTR $7^{+}$and $\mathrm{CCR} 5^{+}$fat-storing multilocular cells in the thymic septa and parenchymal regions, thus suggesting that mesenchymal cells could be immigrating and differentiating in the aging thymus. We verified that the expression of CCR5 and its ligands, CCL3, CCL4 and CCL5, were increased in the thymus with age. Hypothesizing that the increased expression of chemokines and the CCR5 receptor may play a role in adipocyte recruitment and/or differentiation within the aging thymus, we examined the potential role for CCR5 signaling on adipocyte physiology using 3T3-LI pre-adipocyte cell line. Increased expression of the adipocyte differentiation markers, PPARY2 and aP2 in 3T3-LI cells was observed under treatment with CCR5 ligands. Moreover, 3T3-LI cells demonstrated an ability to migrate in vitro in response to CCR5 ligands. We believe that the increased presence of fat-storing cells expressing CCR5 within the aging thymus strongly suggests that these cells may be an active component of the thymic stromal cell compartment in the physiology of thymic aging. Moreover, we found that adipocyte differentiation appear to be influenced by the proinflammatory chemokines, CCL3, CCL4 and CCL5.
\end{abstract}

Key words: thymus, aging, adipocyte, differentiation, chemokines, chemotaxis, involution, adipokines

\section{Introduction}

The adipose tissue is the principal fat reservoir in the body. Unilocular adipocytes are the principal component of white adipose tissue and have a classical role in the regulation of triglycerides and fatty acid accumulation during energy expenditure and depri- vation (1-2). The regulation of adipocyte differentiation is controlled by several factors, including hormones and their receptors that activate proteins and transcription factors such as $\mathrm{CEBP} / \beta$, PPAR- $\gamma$, $\mathrm{CEBP} / \alpha$, aP2 and others (3-4). Besides unilocular 
adipocytes, mesenchymal stem cells and differentiating adipocytes have been described in the adipose tissue making it appear that mesenchymal stem cells under specific stimuli become committed to the adipocyte lineage and able to accumulating lipids thus forming adipocytic multilocular cells, preadipocytes, and ultimately, unilocular adipocytes (1-4).

More recently, several groups have demonstrated that adipose tissue is able to produce proinflammatory cytokines and fat-derived peptides termed adipokines (including ligands such as adiponectin, leptin, resistin, TNF-a, IL-6), which act in a paracrine, autocrine and/or endocrine manner (4-5). The accumulation of adipocytic cells and an increased percentage of fat in several ectopic regions of the body with aging have been well-described (6). This increase also appears to correlate with observed increases in circulating levels of proinflammatory cytokines during aging (7). This is of great interest from an immunological perspective, as the thymus is one of the organs known to accumulate fat during aging and has been shown to be sensitive to inflammatory changes (8-10).

The thymus is a primary lymphoid organ responsible for the differentiation and maturation of $\mathrm{T}$ lymphocytes (10-12). Anatomically, it is a bi-lobed organ subdivided in lobules by septa that emerge from the capsule. Blood vessels and nerves are able to reach the thymic parenchyma by the septa region. In the young thymus, each lobule contains two very well defined regions: the cortex, enriched in immature $\mathrm{T}$ cells; and the medulla, where mainly mature immunocompetent thymocytes can be found, before exiting the organ to populate the periphery. The process of $\mathrm{T}$ cell maturation initiates during fetal development. In post-natal life, progenitors that originated in the bone marrow enter into the thymus and interact with several different thymic stromal cell types, including epithelial cells, macrophages, dendritic cells and fibroblasts, which participate of the T cell differentiation process (10-12). With age, the thymus gradually decreases its capacity to generate immunocompetent $\mathrm{T}$ cells and becomes minimally functional, as it undergoes dramatic changes in its size, morphology and cell composition, a process termed "age-associated thymic involution" (8-10, 13-16). Decreased thymopoiesis, loss of cortical and medullary boundaries, deposition of unilocular adipocytes and changes in the expression of various thymic factors have been shown to occur during this process. This is associated with the increased susceptibility of aged individuals to infectious diseases (10, 17). Thus, investigating the mechanisms that regulate thymic involution and identifying the cells that par- ticipate in this process might contribute to the development of strategic therapies for immunodeficiency conditions, as in the case of aging.

In the current studies, we have investigated the distribution of fat-storing cells in the aging thymus and we found not only an increase of unilocular adipocytes but also an increase of adipocytic-like multilocular mesenchymal cells in the septa and parenchymal regions of the organ. These findings suggest that adipocyte precursors or fat-storing cells may be migrating into and/or differentiating actively within the aging thymic microenvironment. Furthermore, we found that the adipocyte-like cells accumulating in the thymus with age express the chemokine receptor, CCR5. Using the well-characterized adipocytic mesenchymal cell line, 3T3-L1, we found that CCR5 ligands are capable of regulating the migration and differentiation of these cells and suggest a potential role for these chemokines in adipocyte biology.

\section{Material and Methods}

Mice. BALB/c mice bred in the National Institute on Aging rodent colony (Bethesda, MD) were utilized at $2,4,6,9,12,18,21$ and 24 month-old. Mice were housed in environmentally controlled rooms with a $12 \mathrm{~h}$ light-dark cycle according to the procedures outlined in the "Guide for the Care and Use of Laboratory Animals" [NIH publication no. 86-23, 1985]. CCR5-deficient mice (B6;129P2-Ccr5 $5^{\text {tm1Kuz } / J) ~ o r i g i n a l l y ~}$ obtained from Jackson Laboratories (Bar Harbor, ME) were aged in the animal house of the NIAID and kindly donated by Dr. Alan Sher (NIAID/NIH).

cDNA microarray. 1,152 cDNA clones were selected from a verified sequence master set containing 15,000 human T1 phage-negative IMAGE Consortium clones commercially obtained from Research Genetics, Inc. (Huntsville, AL). Nylon membranes were used as substrate for denatured cDNA clone printing in duplicates, using a GMS417 Microarrayer (Affymetrix, Santa Clara, CA). Before the addition of the cDNA probe, the thymi of 2-, 4-, 6-, 12- and 18-month-old BALB/c mice were placed into multiple pools by age for total RNA extraction using RNAzol B (Tel-Test, Friendswood, TX) and cDNA probes were prepared using reverse transcriptase. cDNA microarray membranes were loaded into conical tubes containing Mycrohyb hybridization buffer (Research Genetics) in presence of $0.6 \mu \mathrm{g} / \mu \mathrm{l}$ of Cot1 DNA (Life Technologies) and $0.5 \mu \mathrm{g} / \mu \mathrm{l}$ of poly A primers (Sigma) blocking agents. Tubes were rotated at $42^{\circ} \mathrm{C}$ for 180 min. After prehybridization, ${ }^{33}$ P-labeled cDNA probes (at the concentration of $1 \times 10^{6}$ counts $/ \mathrm{ml}$ hybridization buffer) were added to the tubes with cDNA microarray membranes and hybridized overnight at $42^{\circ} \mathrm{C}$. 
Hybridized membranes were washed twice with 15 $\mathrm{ml}$ of wash solution (0.1\%SDS and 2x SSC) for $15 \mathrm{~min}$ at $55^{\circ} \mathrm{C}$ and at room temperature, respectively. The radioactive cDNA microarray membranes were examined on a phosphorimager (Molecular Dynamics Storm, Sunnyvale, CA) at a resolution of $50 \mu \mathrm{m}$. Grid overlays were utilized to identify cDNA targets on the arrays and signal intensity for each cDNA was examined using the Array Pro software (Media Cybernetics, Silver Spring, MD). Background correction for each cDNA microarray hybridization assay was assessed via the subtraction of single spot intensities by the median of the background signal intensity from the array. The background-subtracted spot intensities were subsequently transformed to $\log _{e}$ scale and ratio comparisons were done using the group of 2 month-old as control.

Real time RT-PCR. $1 \mu \mathrm{g}$ of total RNA isolated from the thymi of 2-, 12- or 18-month-old BALB/C mice was utilized to generate cDNA probes using Taqman Reverse Transcription Reagents (PE Applied Biosystems, Foster City, CA). The SYBR Green I assay and the GeneAmp 5700 Sequence Detection System (PE Applied Biosystems) were utilized for the detection of real-time PCR products as previously described (18). Primers were designed for CCR5, CCL3, CCL4 and CCL5 based on their sequence in GenBank (www.ncbi.nlm.nih.gov/GenBank) as well as for glyceraldehyde-3-phosphate dehydrogenase (GAPDH), which was utilized as control. For each of the age groups, PCR reactions were performed in duplicate in a 96-well plate for each gene-specific primer pair tested. The comparative threshold cycle $\left(C_{\mathrm{T}}\right)$ method (PE Applied Biosystems) was utilized to determine relative quantity of gene expression for each gene compared with the GAPDH control. Briefly, $C_{T}$ values from GAPDH reactions were averaged for each duplicate and the relative difference between GAPDH and each duplicate was calculated $\left(2 C_{T}\right.$ GAPDH - $C_{T}$ experimental). This value was then averaged for each duplicate set and divided by the value of the 2 month-old thymus samples to determine the relative fold induction for each sample. Differences regarding fold change values observed between the cDNA microarray and real-time PCR results might be due to experimental variability in the two distinct assays.

Tissue Array and Immunohistochemistry. Thymi $(n=4)$ of 2, 9, 12, 18 and 21 months of age were mounted in a tissue array as previously described (19). For hematoxylin and eosin staining, sections were deparaffinized in xylene, re-hydrated in graded alcohols and placed at high temperature in solution of $0.01 \mathrm{M}$ sodium citrate buffer ( $\mathrm{pH}$ 6.0) for $40 \mathrm{~min}$. Sections were then stained with hematoxylin (Lerner
Laboratories), rinsed and differentiated with $1 \%$ acidic alcohol before eosin (Lerner Laboratories, Pittsburgh, PA) staining, dehydrated in graded alcohol and then mounted in organic media. For peroxidase immunohistochemistry, a standard two-step Dako Autostainer (Dako Corporation, Carpenteria, CA) was utilized to examine the thymic sections. An antigen retrieval procedure was utilized to recover antigenic sites from tissue sections. Primary purified rabbit anti-mouse CCR5 (BD PharMingen, CA), rabbit anti-CCL3, -CCL4 (R\&D Systems, MN) or -CCL5 (Chemicon, CA) IgG antibodies were applied on thymic sections at $10 \mu \mathrm{g} / \mathrm{ml}$ for $60 \mathrm{~min}$ at room temperature in moist humidified chamber. After extensive washing, tissue sections were incubated with peroxidase-conjugated donkey anti-goat, goat anti-rabbit or rabbit anti-rat (Santa Cruz Biotechnologies) antibody, for $30 \mathrm{~min}$, after which the sections were extensively washed and then immersed in a freshly prepared chromogen/substrate reagent (diaminobenzidine, DAB/ Hydrogen peroxide, $\mathrm{H}_{2} \mathrm{O}_{2}$ ). Slides were mounted using an organic media (Cytoseal $^{\mathrm{TM}} 60$, Stephens Scientific, Riverdale, NJ). PBS, pH 7.4, was used for all intermediate wash steps.

For immunofluorescence, rat anti-mouse fibroblast/ mesenchymal cells (ER-TR7) (Novus Biologicals, Littleton, CO) IgG antibody was used at $10 \mu \mathrm{g} / \mathrm{ml}$ for $60 \mathrm{~min}$. After PBS washing, slides were incubated with anti-rat IgG antibody conjugated to Alexa-594 (Molecular Probes, Eugene, OR). Subsequently, slides were washed, incubated with the DNA dye DAPI (4',6-diamidino-2-phenylindole) and mounted using glycerol $50 \%$ aqueous mounting media.

Oil Red O staining. Oil red O (Fischer Scientific, Hanover Park, IL) was diluted in 50\% propylene gly$\mathrm{col}$, and filtered. Thymic tissue sections were incubated with Oil Red O solution for $4 \mathrm{~h}$ at room temperature and then rinsed with 50\% isopropyl alcohol and in distilled water before hematoxylin staining, for $2 \mathrm{~min}$. Slides were then rinsed with ammonia 5\% in water, blot dried and mounted with glycerol 50\% aqueous mounting media.

Cultures of 3T3-L1 preadipocytes for differentiation analysis. Cells were cultured in Dulbecco's minimal essential medium (DMEM) supplemented with $10 \%$ calf serum until confluence (6-7 days). Then, confluent 3T3-L1 preadipocytes were treated for 9 or 12 days with $100 \mathrm{ng}$ of CCL3, CCL4 or CCL5 (Chemicon, CA). Culture medium was changed every three days. Subsequently, differentiation of 3T3-L1 cells was analyzed by lipid accumulation under light microscope and by western blot analysis for adipocyte differentiation markers.

Western Blot analysis. 3T3-L1 cells were lysed in 
1.5x Laemlli sample buffer and proteins were quantitated by Bradford reagent (Bio-Rad, Hercules, CA). After heating for $5 \mathrm{~min}$ at $95^{\circ} \mathrm{C}$, proteins were separated by SDS-PAGE on $12 \%$ polyacrylamide gel and transferred onto $0.22 \mu \mathrm{m}$ polyvinylidine (difluoride) membranes (Invitrogen). Membranes were probed with rabbit anti-PPARY2 (Affinity BioReagents, CO) or rabbit-anti-aP2 (GeneTex, TX) antibodies. Signal detection was performed by chemiluminescence (ECL) using Hyperfilm (Amersham Biosciences).

Migration assay. 3T3-L1 preadipocytes were placed in fibronectin-coated plates (BD Biosciences, CA) in DMEM medium. After two days post-confluence, cells were treated in the absence or in the presence of CCL3, CCL4 or CCL5 $(100 \mathrm{ng} / \mathrm{ml})$ for 16h. A wound was inflicted with a sterile plastic tip by scratching the confluent monolayer. Cells moving into the scratch were observed over several time points using light microscopy.

\section{Results}

Fat-storing multilocular cells increase within the thymus with advancing age. Tissue arrays were used to characterize the phenotype of adipocytic cells within the thymus of aging mice. Histological and morphological analyses indicated an age-dependent increase in adipose tissue deposition, including unilocular adipocytes and multilocular cells. Upper panels of Figure 1 represent the thymus of 2, 12 and 21 month-old mice stained for hematoxylin and eosin. In the thymus of 2 month-old mice the cortical and medullary regions were well-defined and very few or no adipocytes were observed in the septa region or inside the organ (Figure 1A). A progressive deposition of unilocular adipocytes was mainly seen in the thymic perivascular space (PVS), as shown in the representative photomicrography of 12 month-old murine thymus (Figure 1B). Interestingly, in some thymic tissue sections of 18 month-old animals, isolated adipocytes were observed in the subcapsulary region of the organ (not shown) and fibroblastoid cells were visualized inside the thymic parenchyma. These fibroblastoid cells were observed connected to the capsule, thus creating a boundary-like structure in the subcapsulary region of the organ (Figure $3 \mathrm{H}$ ). As expected, as thymus aged, a decrease in the number of thymocytes was seen in the cortex and loss of cortical and medullary boundaries were observed in the thymic lobules (Figure 1).

To further investigate the presence of fat-storing cells in the aging thymus, we performed Oil Red O staining in frozen mouse thymic tissues. Increased number of multilocular Oil Red $\mathrm{O}^{+}$cells was observed inside the thymus with aging (Figure $1 \mathrm{D}-\mathrm{I}$ ). While the thymi of 2 month-old mice showed few, if any, Oil Red $\mathrm{O}^{+}$multilocular cells, mice at 4 and 6 months of age presented fat-storing cells mainly in the septa region of the organ (not shown). Moreover, Oil Red $\mathrm{O}^{+}$multilocular cells were observed in the thymic septa and in the thymic capsular regions of 12 month-old mice. Finally, a higher number of Oil Red $\mathrm{O}^{+}$multilocular cells were visualized in the septa region and inside the thymic parenchyma of 12 and 24 month-old thymi (Figure 1). These data lead us to propose that adipocytic/mesenchymal cells may be migrating to the aging thymus and behaving as a thymic stromal cell component able to interact closely with differentiating thymocytes and other microenvironmental cells in the aging thymus.

Age-dependent thymic expression of CCR5 chemokine receptor. Based on the possibility that adipocytic/mesenchymal cells could be immigrating into the thymus, we looked for genes that significantly changed with age and are known to be involved in cell migration. Using cDNA microarray technology, changes in thymic gene expression profiles were analyzed as a feature of aging. One of the genes identified was CCR5, a chemokine receptor known to bind to the proinflammatory chemokines CCL3, CCL4 and CCL5. Previous data have demonstrated that CCR5 participates in T cell migration and activation (20). In addition, CCR5 has been shown to be expressed in $\mathrm{T}$ cells, macrophages and, interestingly, human adipocytes and 3T3L1 preadipocyte cell line (21-23). We analyzed the expression of CCR5 mRNA and found that it was increased in the aging thymus, as detected by cDNA microarray and confirmed by real time RT/PCR (Figure 2). Flow cytometric analyses revealed that only 1 to $2 \%$ of total mouse thymocytes express CCR5, independently of age (data not shown), indicating that this increase may be attributable to CCR5 production by thymic stromal cells. 

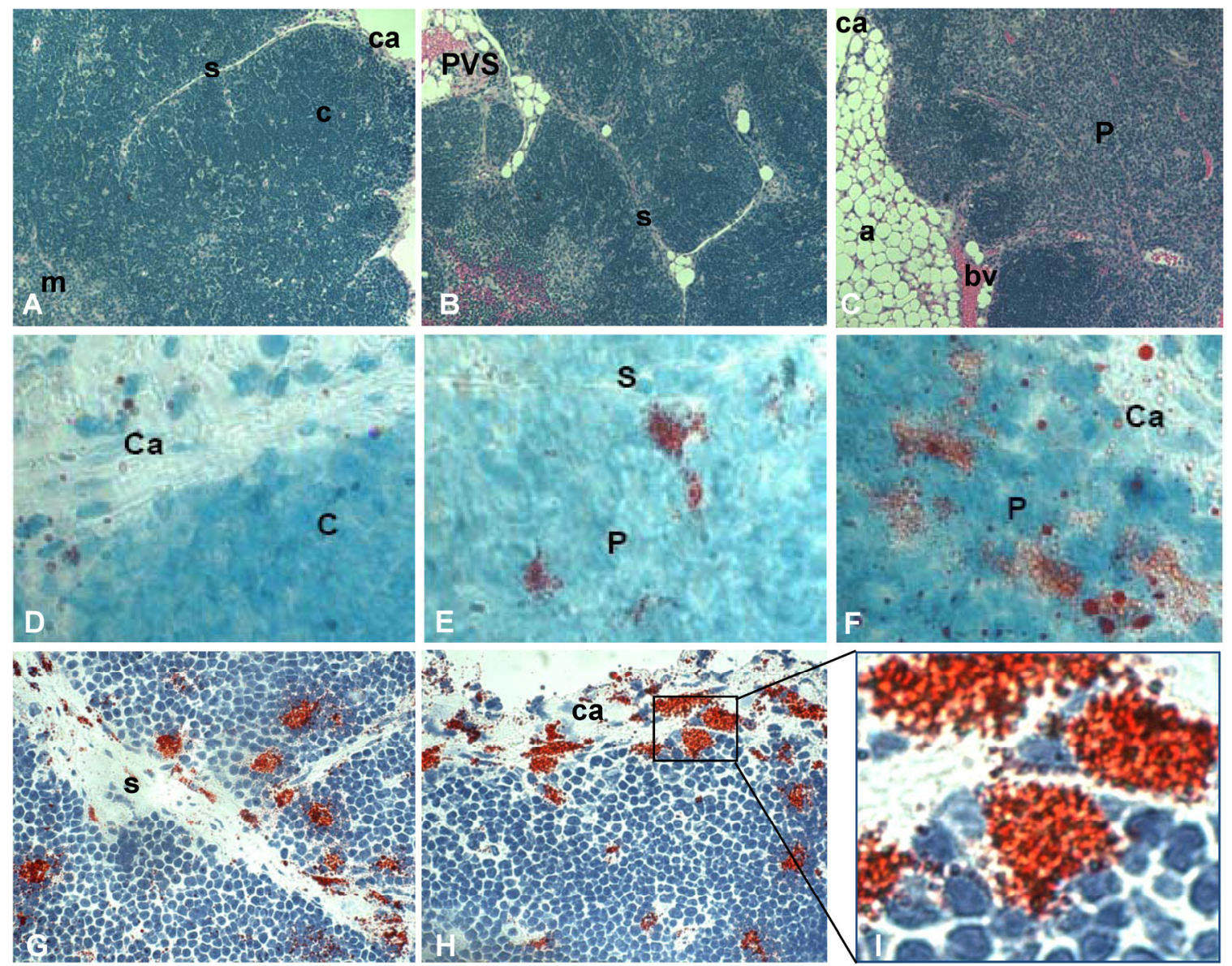

Figure I. Increase of fat-storing cells within the murine thymus with advancing age. Photomicrographs of thymus paraffin sections $(5 \mu \mathrm{m})$ derived from mice of distinct ages were stained with hematoxylin and eosin (A-C). Fat-storing multilocular cells were stained with Oil Red $\mathrm{O}(\mathrm{red})$ and hematoxylin following cryosection of thymic tissue (D-F). $A$ and $D, B$ and $E$ and $C$ and $F$ are representative photomicrographs for groups of mice with 2,12 and more than 18 months of age, respectively. In $\mathrm{G}$ and $\mathrm{H}$, fat-storing multilocular cells (red) are shown in the capsule, septa and inside the parenchyma of mice with 12 months of age. (I) shows zoom of marked region in figure $\mathrm{H}$ with fat-storing multilocular cells contacting thymocytes in the thymic subcapsulary region. Ca, capsule; s, septa; c, cortex; m, medulla; bv, blood vessel, P, parenchyma. Original magnification: 400x (A,B,C); $1000 x(\mathrm{D}, \mathrm{E}, \mathrm{F}) ; 630 \times(\mathrm{G}, \mathrm{H}, \mathrm{I})$.

Figure 2. CCR5 mRNA expression in the aging thymus. (A) cDNA microarray filters hybridized to total RNA isolated from thymi between 2 and 18 months of age. Arrows indicate spot corresponding to CCR5 mRNA expression. (B) Graphic representation of CCR5 mRNA expression according to cDNA microarray results for thymus of $2,4,6,12$ and 18 months of age. (C) CCR5 mRNA expression of thymus of 2,12 and 18 months old was compared using real time RT/PCR analysis.
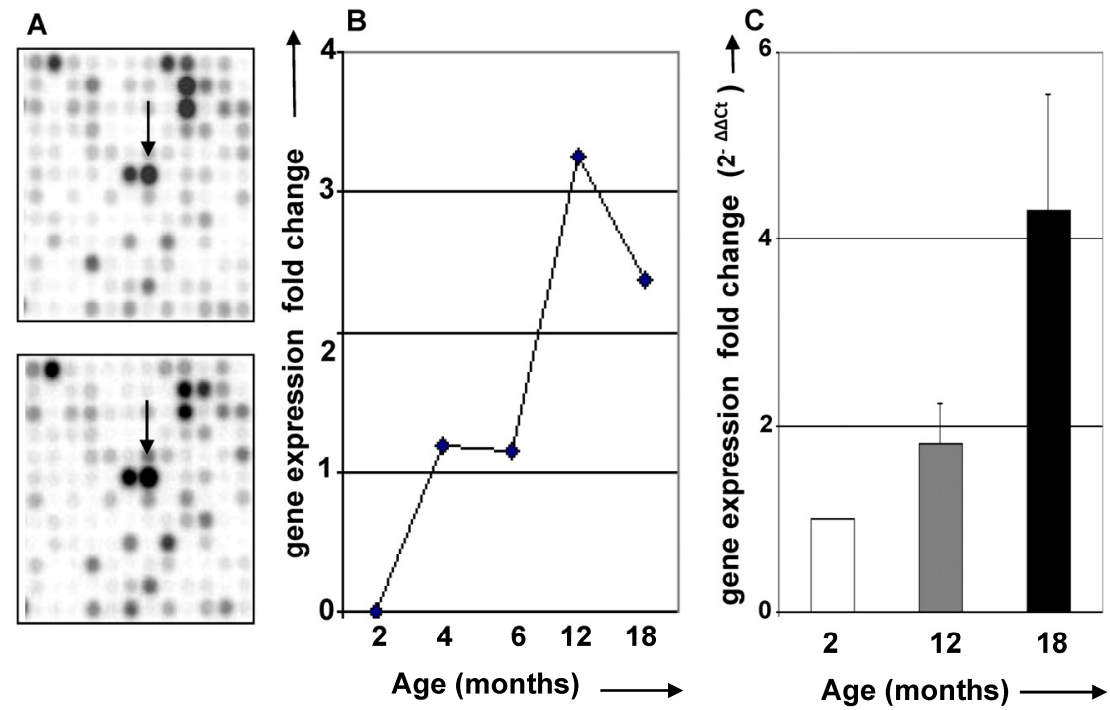

http://www.medsci.org 
CCR5 expression in the aging thymus is mainly detected in fat-storing multilocular cells. To substantiate the above observations, we performed immunohistochemical analysis of our thymic tissue array and demonstrated an increase of CCR5 expression in the aging thymus (Figure 3). Although some thymocytes stained positive for CCR5 were observed, the main thymic cell type expressing CCR5 resembled adipocytic-like multilocular cells or fat-storing cells. These cells were mainly found in the septa region, adjacent to adipocytes, and also in the thymic parenchyma, interacting with thymocytes and thymic microenvironmental cells (Figure 3). Morphologically, $\mathrm{CCR}^{+}$multilocular cells and fibroblastoid cells were present in the perithymic adipose tissue as well as in the perivascular space in the septa and capsule. Additionally, these cells were visualized in the subcapsulary region of aged thymi and inside the thymic aged parenchyma in contact with thymocytes (Figures 3). Serial sections of thymic tissue arrays showed that these multilocular cells stained positively for ER-TR7, a known marker for murine mesenchymal cells (Figure 4).

Expression of CCR5 ligands is enhanced in the aging thymus. To further investigate a possible role for CCR5 on immigration of fat-storing cells, we examined the expression of CCR5 ligands in the aging thymus. Real time-RT-PCR analysis showed that the expression of CCL3, CCL4 and CCL5 mRNA increased in thymus and total thymocytes with age (Figure 5). Using immunohistochemical method, thymocytes and thymic stromal cells stained positively for CCL4 and CCL5 (Figure 6). Interestingly, in the septa region of the thymus of 2 month-old mice, CCL4 expression was detected in cells resembling pericytes and myofibroblasts, mesenchymal cell types (Figure 6). In the thymus of 12 months of age, CCL4 expression was observed in thymocytes and in multilocular cells in the septa and inside the thymic parenchyma. These data reinforced the hypothesis that adipocytic mesenchymal cells could be possibly immigrating and/or differentiating in the aging thymus by an active process regulated by CCR5 ligands.

Intrathymic fat-storing cells are present in aged CCR5-deficient mice. The possibility that CCR5 ligands could be influencing immigration of adipocytic mesenchymal cells into the aging thymus lead us to investigate whether Oil Red $\mathrm{O}^{+}$cells could be visualized in thymi of 10-11 month-old CCR5-deficient mice. Both aged CCR5-deficient mice and wild type control group presented Oil Red $\mathrm{O}^{+}$multilocular cells in the septa and in the cortical region of the thymus (Figure 7). Although the number of Oil Red $\mathrm{O}^{+}$cells in
CCR5-deficient mice was lower than in control group, this difference was not statistically significant. Moreover, there was no significant histological change between CCR5-deficient and control thymi stained for hematoxylin and eosin (data not shown).

CCR5 ligands regulate differentiation and migration of 3T3-L1 adipocytic multilocular mesenchymal cells in vitro. Due to the lack of specific surface markers for adipocytic multilocular mesenchymal cells and technical difficulties to isolate them, we chose to analyze the effects of CCR5 ligands in murine 3T3-L1 cells, a well-characterized embryonic mesenchymal cell line known to differentiate into adipocytes in vitro $(24,25)$. To investigate the role of CCR5 ligands in 3T3-L1 cells, immunocytochemistry was used to verify the expression of ER-TR7 and CCR5. The results confirmed that preadipocytes in culture express CCR5 (Figure 8A). In addition, 3T3-L1 cells in differentiation also expressed CCL3, CCL4 and CCL5, thus suggesting that these chemokines could possibly act in an autocrine and paracrine manner (Figure 8A).

The differentiation of 3T3-L1 cells is routinely carried out by the addition of dexamethasone, insulin and isobutyl-methyl-xanthine to the culture medium $(24,25)$. However, in the absence of these specific factors, 3T3-L1 cells are able to differentiate spontaneously although to a much slower rate. To analyze if CCR5 ligands would be able to stimulate differentiation of 3T3-L1 cells to adipocytes, CCL3, CCL4 or CCL5 was added to the culture medium of confluent cells for nine or twelve days. These chemokines were found to stimulate the differentiation of 3T3-L1 cells, as evidenced by the increase expression of the adipocyte differentiation markers, PPARY2 and aP2 (Figure $8 \mathrm{~B})$. By the ninth day of culture, the number of refringent multilocular cells accumulating lipids was higher in CCR5 ligand-treated cells when compared to untreated cells. This observation was even more evident at twelve days of culture (Figure 8C).

We also investigated the influence of CCL3, CCL4 and CCL5 on the migration of multilocular mesenchymal cells in vitro. 3T3-L1 cells were cultured in fibronectin coated-plates and two days post-confluence, cells were treated with CCL3, CCL4 or CCL5 for 20h, followed by scratching of the plate. As indicated in figure 9A, after 20h, higher cell motility was observed in the plates treated with all three CCR5 ligands, as compared to untreated cells, and the treatment of CCL5 elicited the strongest effect. Taken together, these results show that CCR5 ligands are able to modulate adipocyte differentiation as well as the migration of 3T3-L1 adipocytes. 

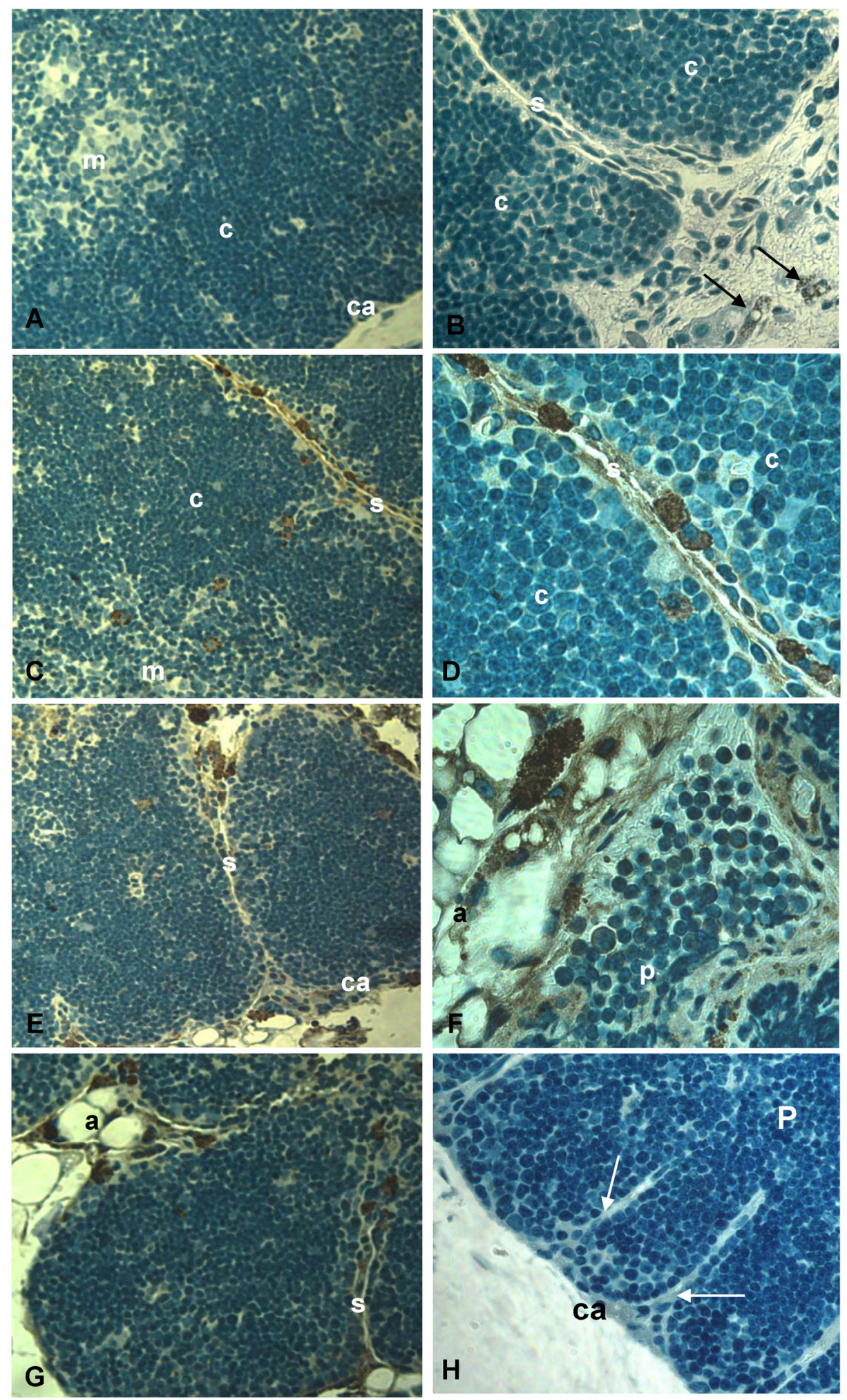

Figure 3. CCR5 expression in histological thymic sections of aging mice. Thymus sections of mice with $2,9,12$ and 18 months of age were submitted to immunoperoxidase using rabbit anti-mouse CCR5 Ab (A-G) or unspecific rabbit $\lg G(H)$. Counterstaining was done with hematoxylin. CCR5 was detected in multilocular cells in the septa, parenchyma and adipose tissue (C-G) as well as in thymocytes $(\mathrm{F})$. Black arrows indicate $C C R 5^{+}$mesenchymal cells in the perithymic adipose tissue (B). White arrows point to fibroblastoid cells originating from the thymic capsule $(\mathrm{H})$. A, adipocyte; $\mathrm{Ca}$, capsule; $\mathrm{C}$, cortex; M, medulla; P, parenchyma; S, septa; mo, months of age. Original magnification: 630x (left) and I000x (right). 


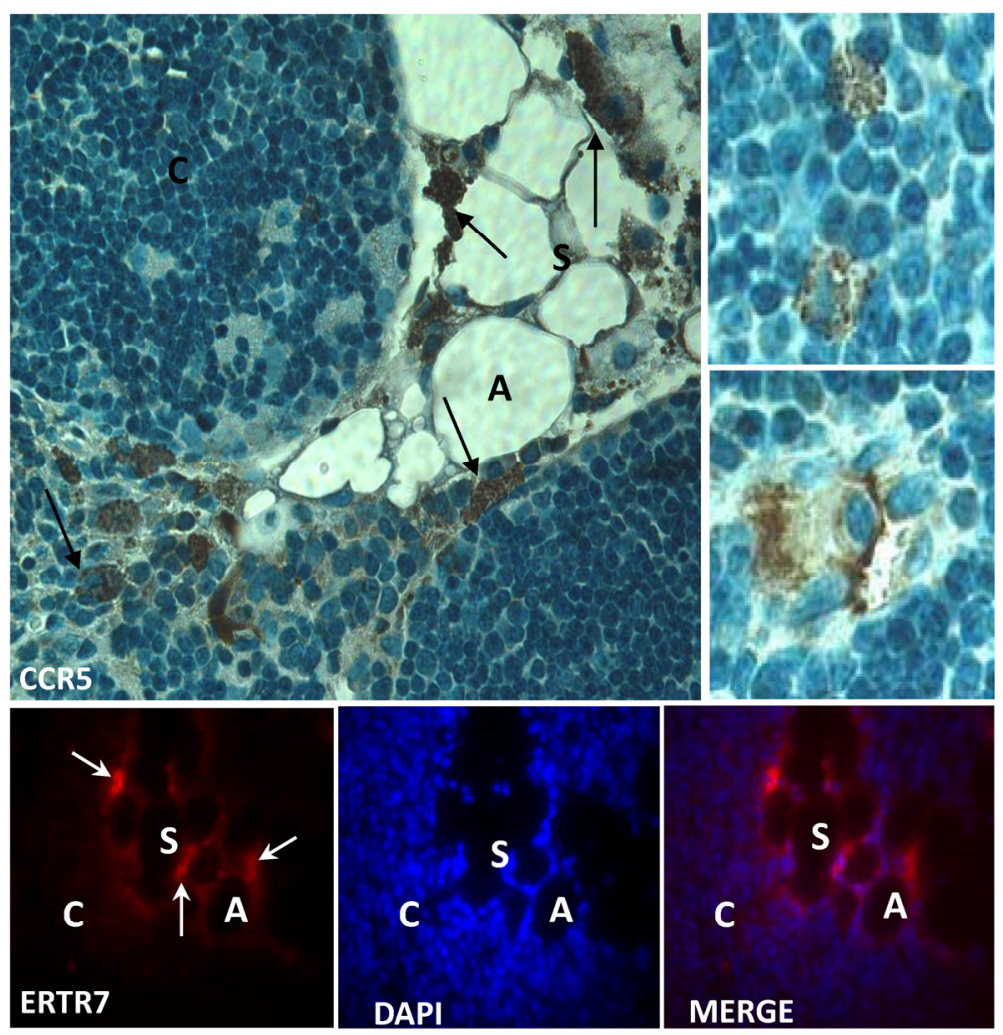

Figure 4. Expression of CCR5 and ERTR7 in multilocular mesenchymal cells in the aged thymus. Upper panels show histological sections of 21 month-old thymus containing CCR5-positive cells, by immunoperoxidase. Counterstaining was done with hematoxylin. Upper small panels on the right show CCR5+ multilocular cells inside the thymic parenchyma interacting with thymocytes and stromal cells. Lower panels show multilocular cells stained for ERTR7 (red) and the nuclei dye DAPI (blue), by immunofluorescence. Black arrows indicate $\mathrm{CCR}^{+}$multilocular cells. White arrows indicate ERTR7 ${ }^{+}$multilocular cells. A, adipocyte; C, cortex; S, septae. Original magnification: Upper panels, I000x; lower panels, 630x.
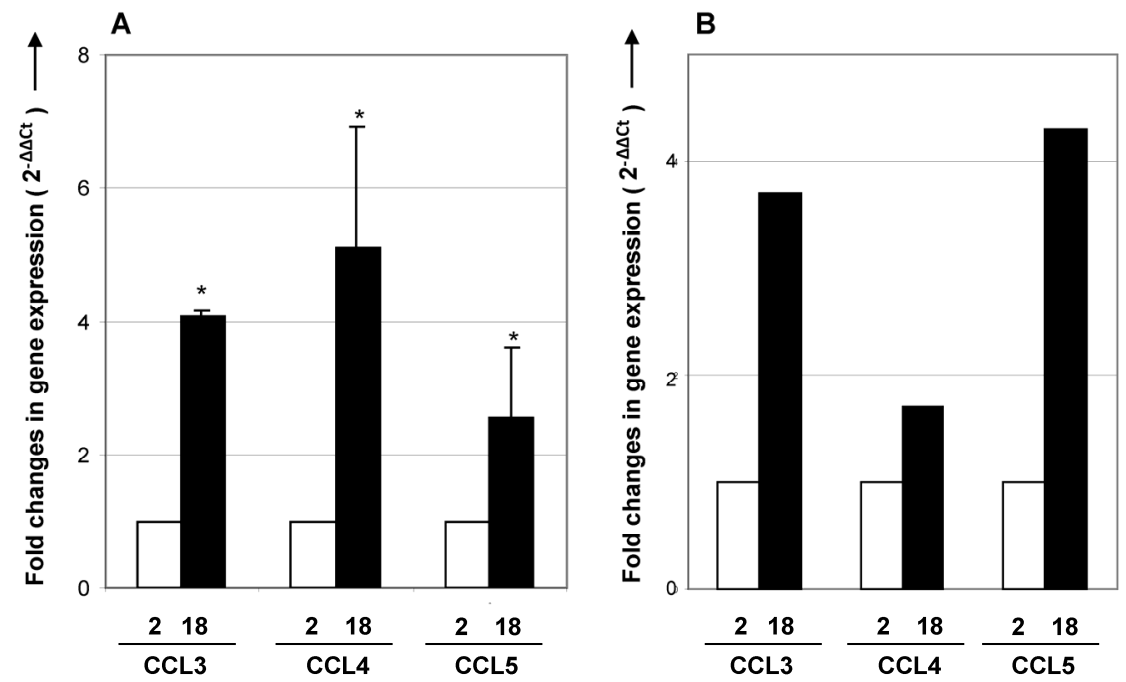

Figure 5. CCR5 ligands mRNA expression in thymus and thymocytes of young and aged mice. cDNA obtained from thymus (A) or total thymocytes (B) by reverse transcription using RNA isolated from 2-and I8-month-old mice were analyzed by real time RT-PCR. Specific primers to CCL3, CCL4 and CCL5 were utilized. The comparative threshold cycle $\left(C_{T}\right)$ method was utilized to calculate fold change (mean $\left.\pm S D\right)$ between age groups. Student's $t$ test $\left(*_{\mathrm{P}}<0.05\right)$. 

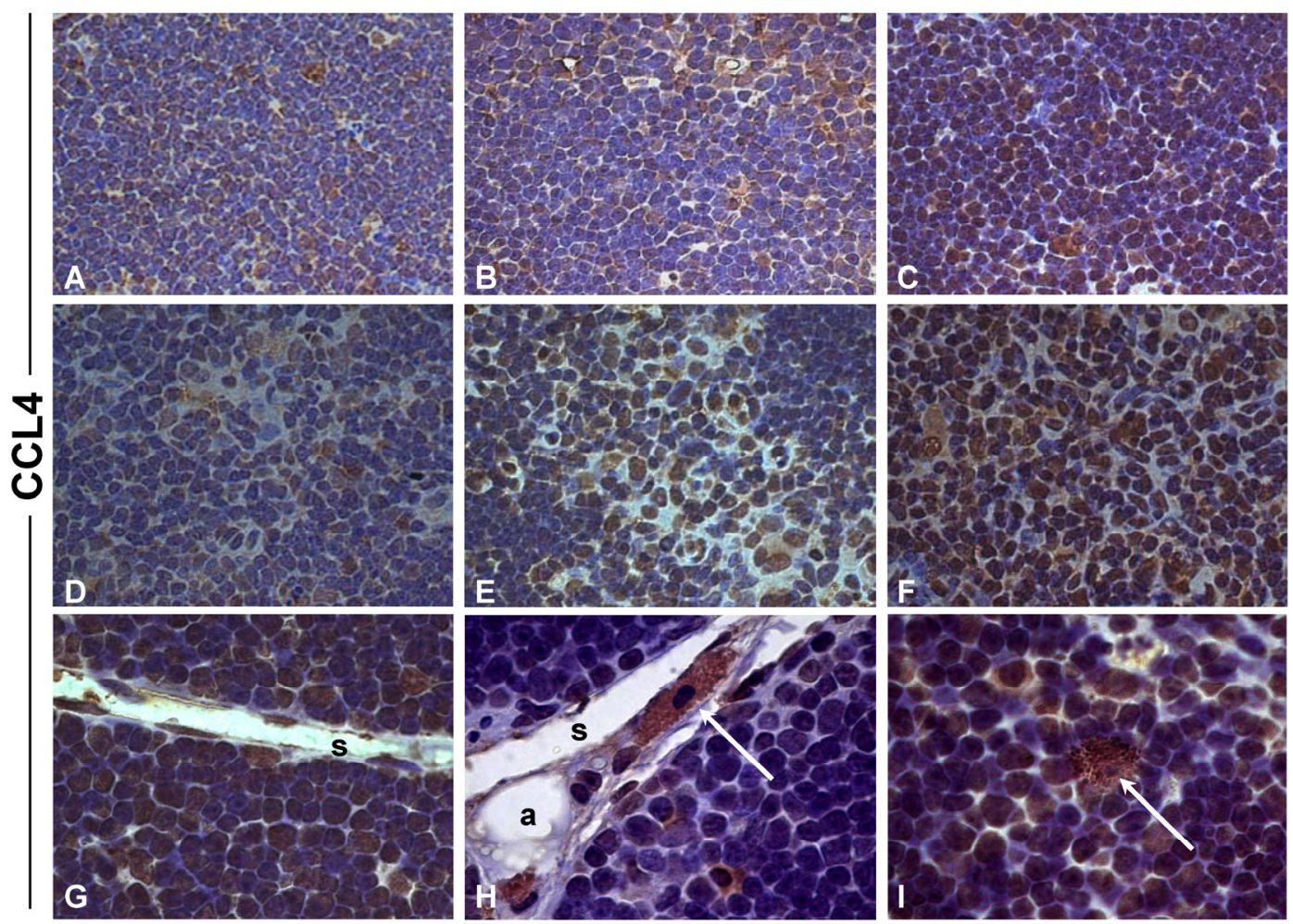

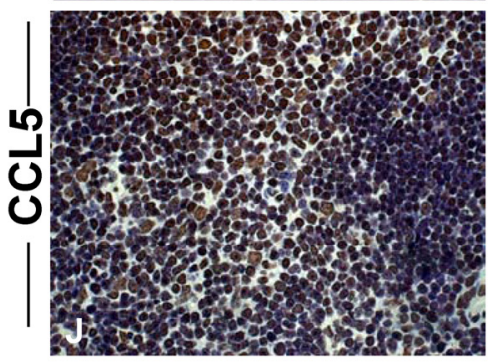

2 month-old

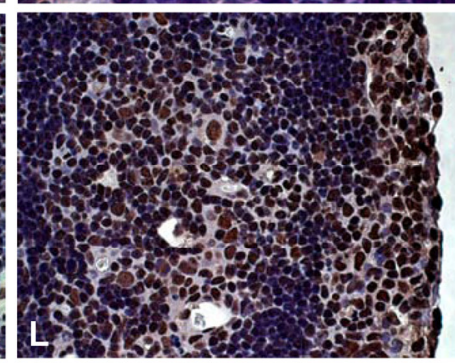

12 month-old
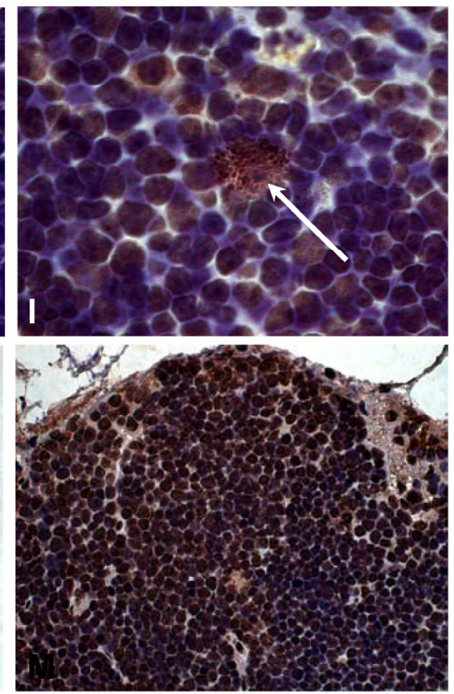

18 month-old

Figure 6. Increased expression of CCL4 and CCL5 in the thymus with age. Histological sections of thymus obtained from $2(A, D, G, J), I 2(B, E, H, L)$ and I $8(C, F, I, M)$ month-old mice were submitted to immunoperoxidase staining using rabbit-anti-CCL4 or anti-CCL5 antibodies. Counterstaining was done with hematoxylin. CCL4 and CCL5 were detected in thymocytes and stromal cells in the thymic parenchyma. Multilocular cells positively stained for CCL4 were seen in the thymic septa $(\mathrm{H})$ and parenchyma $(\mathrm{I})$ of mice with 12 and 18 months of age. Arrows indicate $\mathrm{CCL}^{+}$cells resembling pericytes or multilocular mesenchymal cells in the septa region or inside the thymic parenchyma. C, cortex; $\mathrm{M}$, medulla; $\mathrm{P}$, parenchyma; $\mathrm{S}$, septa; pe, pericytes. Original magnification: 630x (J-M); 1000x (A-I).

Figure 7. Fat-storing multilocular cells in the thymus of CCR5-deficient mice. Frozen thymic sections were obtained from 10-II month-old CCR5-deficient mice $(n=3)$. Histological sections were stained for Oil Red $\mathrm{O}$ to identify cells accumulating lipids. Oil Red $\mathrm{O}^{+}$cells were observed in the thymic parenchyma of control and CCR5-deficient mice (green arrows).
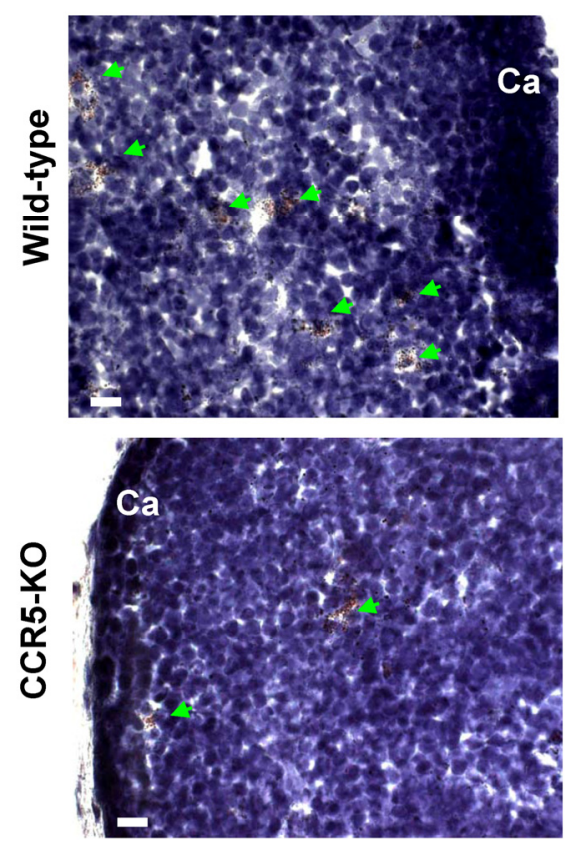
A
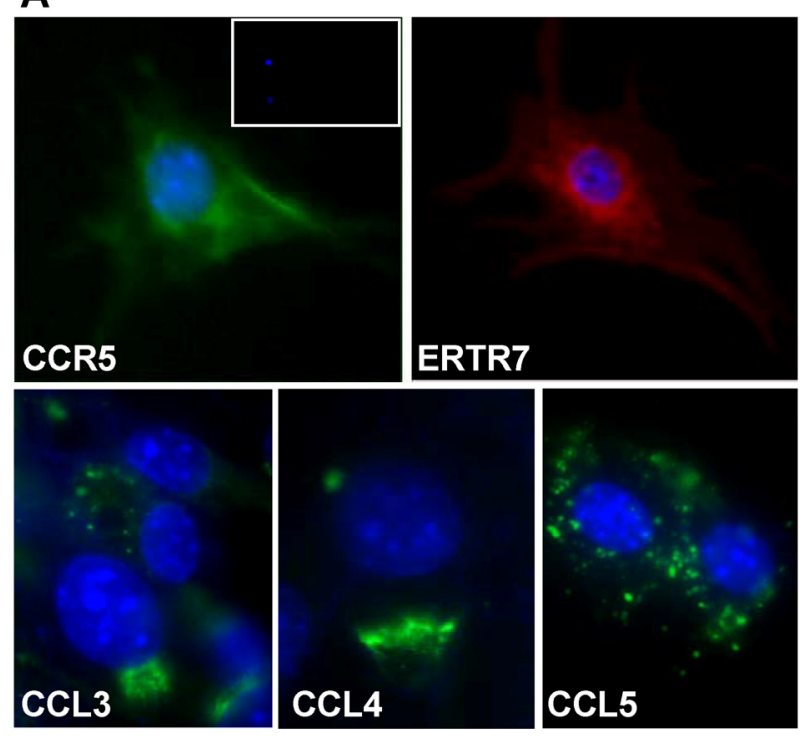

B

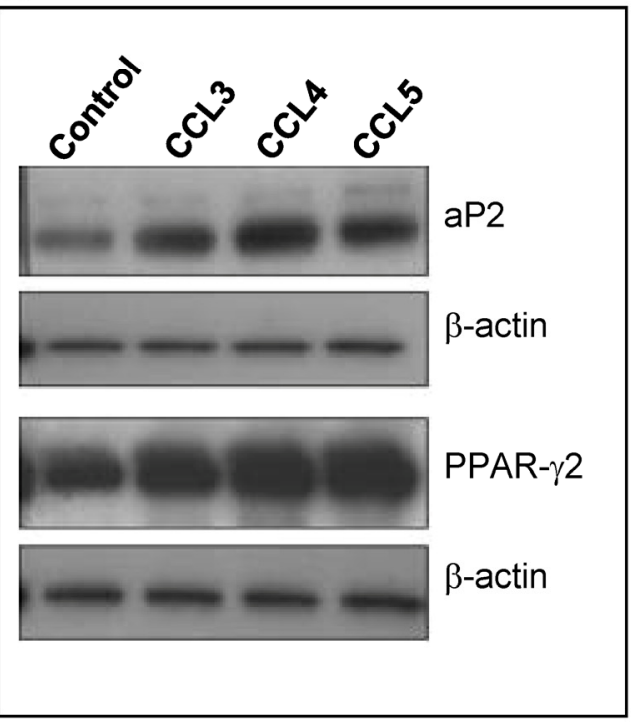

C
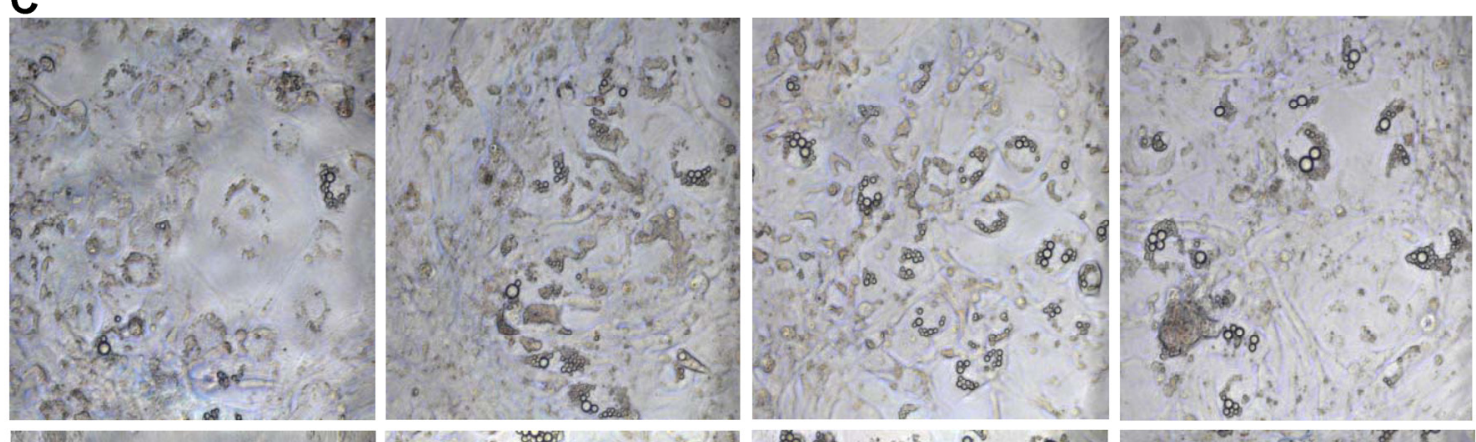

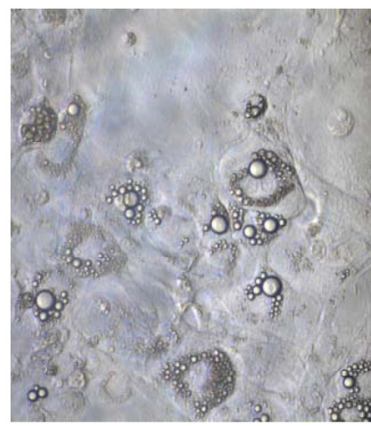

Control

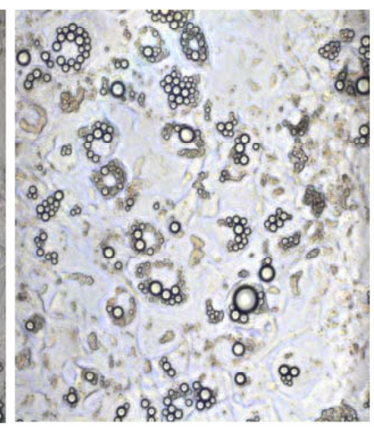

CCL3

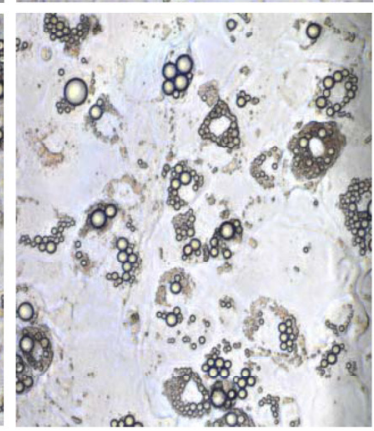

CCL4

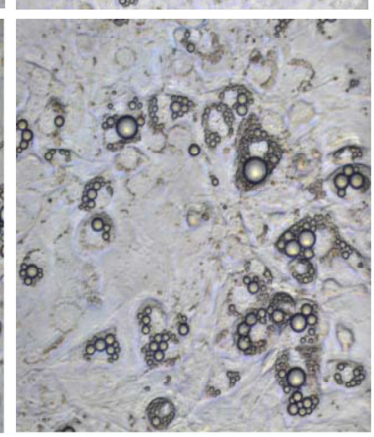

CCL5

Figure 8. CCR5 ligands promote adipocyte differentiation in vitro. (A) 3T3-LI cells were fixed and stained, by immunofluorescence, with specific antibodies for mesenchymal cells, ERTR7 (red), and either CCR5 (green), CCL3 (green), CCL4 (green) or CCL5 (green) and the nuclei dye DAPI (blue). Insert shows DAPI and IgG control staining. (B) Confluent $3 T 3-\mathrm{LI}$ cells were treated with $100 \mathrm{ng} / \mathrm{ml}$ of CCL3, CCL4 or CCL5 for 9 days. After, cell extracts were prepared and analyzed by Western blot using antibodies to the adipocyte differentiation markers PPARY2 and aP2 as well as to $\beta$-actin, as loading control. (C) Increased number of cells differentiated towards adipocyte was observed in confluent 3T3-LI cells cultured for 9 days (upper panel) and 12 days (lower panels), following treatment in the presence of CCR5 ligands. Chemokines were added every three days in culture media. 

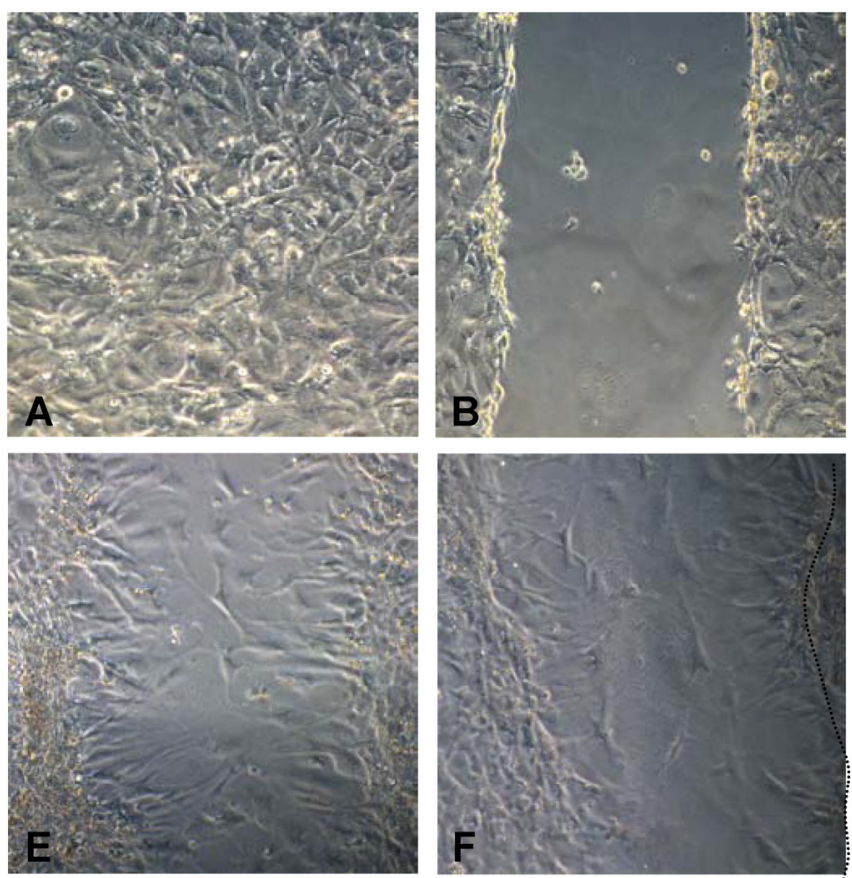
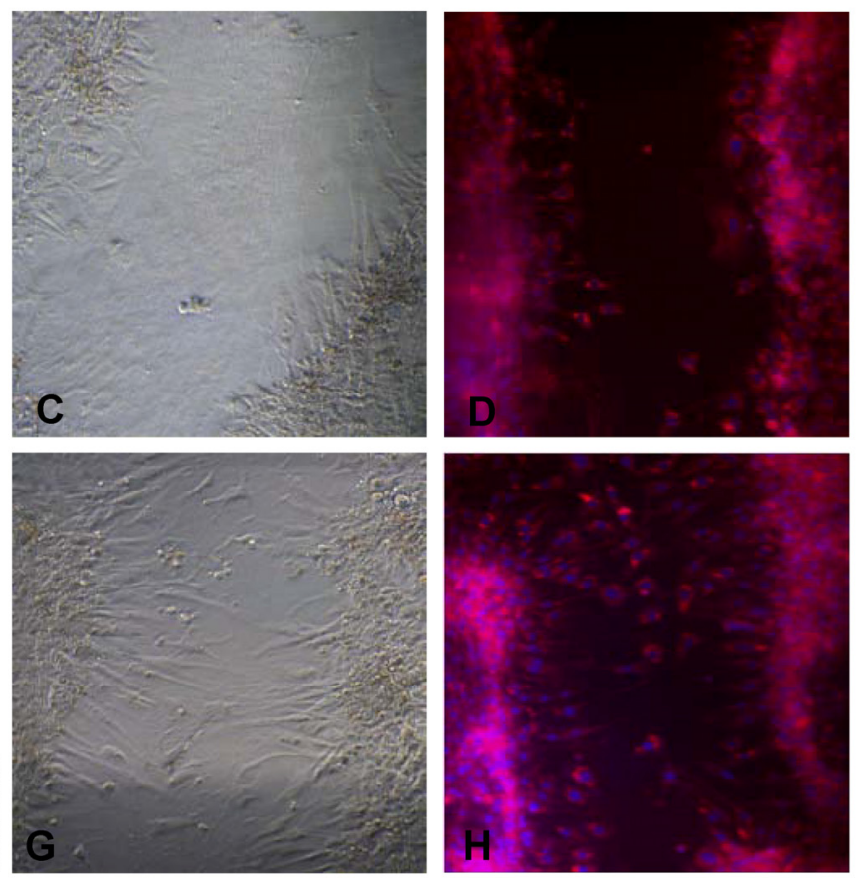

Figure 9. Migration of 3T3LI preadipocytes is stimulated by CCR5 ligands in vitro. 3T3-LI cells were grown to confluence on fibronectin-coated plates (A). The plates were then scratched utilizing a plastic tip (B) and treated or not (C, D) for $20 \mathrm{~h}$ with $100 \mathrm{ng} / \mathrm{ml}$ of CCL3 (E), CCL4 (F) or CCL5 (G, H). After $20 \mathrm{~h}$, control (D) and CCL-5 treated cell cultures (Panel $\mathrm{H}$ ) were fixed and submitted to Nile Red and DAPI staining. Cells were observed in phase contrast (A-C, E-G) or under fluorescent microscopy $(D, H)$. Migrating cells were observed in the space left by the scratch in the wells. Original magnification: 400x.

\section{Discussion}

Within the young thymus, several cell types have been described as playing a role in thymic physiology including thymocytes, thymic epithelial cells, dendritic cells, fibroblasts, mesenchymal cells and a variety of hematopoietic cells, such as macrophages, NK and B cells $(25,26)$. However, alterations in numbers, distribution and function of these thymic cellular components during the aging process are poorly known. In this work, we suggest that adipocytes and fat-storing cells may be an active component during thymic atrophy associated with age. In this context, unilocular adipocytic cells have been described to fill the space left by the receding lymphoid thymic compartment as thymus age $(9,27,28)$. It is known that adipocyte deposition occurs in the aging thymus possibly due to the loss of thymopoiesis and increase of thymic interlobular spaces, characteristics of thymic involution $(10,27,28)$. In agreement, our histological analysis show progressive age-dependent alterations in the thymic organ, with unilocular adipocytes accumulation in the mouse thymic perivascular space $(9,27-29)$. In addition, our data also show interaction between unilocular adipocytes with thymocytes and thymic stromal cells inside the thymic parenchyma. These observations suggest a possible functionality to adipocytic cells in the thymus which conflicts with the general belief that during aging, adipocytic unilocular cells simply fill a space left by the thymic lymphoid compartment or replace the lymphocytic perivascular space.

In the present study, we defined not only thymic unilocular adipocytes in the thymus but also fat-storing multilocular mesenchymal cells, based on their morphology, Oil Red O and ERTR7 staining. We found that the presence of fat-storing cells inside the murine thymic parenchyma and septa region with age is in accordance with a previous study showing the ultrastructure of adipocytic multilocular cells in the thymus of rats and mouse (30). Interestingly, Oil Red $\mathrm{O}^{+}$cells were shown within the perivascular space of human thymus (31). However, these authors failed to comment on the presence of adipogenic multilocular cells within the aged human thymus.

An increased number of fat-storing multilocular cells within the aging thymus were also observed in our study. However, how these cells appear in the thymus and their function is unknown. We hypothesize at least three ways that these cells could appear in the organ. One hypothesis is that adipogenic multi- 
locular cells could be differentiating from mesenchymal cells known to be present in the thymic parenchyma since fetal life (32). It is also possible that fat-storing multilocular cells could be differentiating from pericytes associated with endothelial cells in blood capillaries of the thymus. In this context, pericytes have the potential to differentiate to distinct mesenchymal cell lineages, including the adipocytic one $(33,34)$. Third, the immigration of adipocytic precursors from the perithymic adipose tissue or circulation may result in adipocytic multilocular cell accumulation in the aging thymus. Recently, bone marrow mesenchymal stem cells were found to migrate from the circulation to several tissues, including the thymus $(35,36)$. Finally, the possibility that all these events are happening conjointly during the process of aging cannot be ruled out.

Our results show an age-associated increase in CCR5 mRNA expression in the thymus that correlates with an increased number of CCR $5^{+}$multilocular cells within the thymic capsule, septa and in the parenchyma of the organ. In this context, CCR5 expression has been previously found in human adipocytes in vitro and in human adipose tissue in situ as well as in 3T3L1 preadipocyte line in culture $(25,37)$. Thus, the possibility that the chemokine receptor CCR5 could be regulating adipocyte migration was investigated. Toward this end, CCR5 ligands mRNA expression increased in the aging thymus. The CCR5 ligands, CCL4 and CCL5, increase in the thymic parenchyma as revealed by the age-associated increases in the staining of thymocytes and microenvironmental cells, including the multilocular fat-storing cells. These data suggest that chemokines may influence the migration and possibly the differentiation of adipogenic or fat-storing cells within the aging thymus. However, our observations showing no significant differences in the number of fat-storing multilocular cells using 11 month old CCR5-deficient versus wild type mice (although a trend of lower adipocyte numbers was observed) failed to support a role for CCR5 in adipocyte development in the aging thymus. However, these data also raised two possibilities. First, the progenitors of these adipocyte-like cells could be thymic mesenchymal cells that are known to be present in the thymus parenchyma (31) and whose phenotype may be modified during the aging process. Second, other chemokine receptors could be acting in the migration of adipocytic mesenchymal cells to the aging thymus of CCR5-deficient mice. However, it should be noted that we were quite limited with the number of aged CCR5 deficient mice available to us to examine here and additional studies may provide more conclusive data regarding the role of distinct chemokine recep- tors in adipogenic mesenchymal cell immigration and/or differentiation within the aging thymus.

Interestingly, we have found that the CCR5 ligands, CCL3, CCL4 and CCL5, without any other stimuli, were able to induce adipogenesis using the 3T3-L1 mesenchymal cell line, as evaluated by the increased expression of PPAR 2 and aP2 $(38,39)$. To our knowledge, this is the first time CCR5 ligands are described to stimulate adipocyte differentiation. While these data do not directly demonstrate the ability of chemokine ligands to facilitate primary mesenchymal cell differentiation to the adipocyte lineage, these experiments support the idea that chemokines may be possibly acting as chemoattractants for adipogenic mesenchymal and/or fat-storing cells, facilitating their immigration and possibly their subsequent differentiation within the aging thymic microenvironment. Although additional work will be needed to establish a role for adipogenic cells in the thymus, several groups have shown thymic atrophy in transgenic mice harboring defects in adipocyte physiology, such as ob/ob (leptin), db/db (leptin receptor) and corticotropin-releasing factor overexpressing mice $(40,41)$. In this context, reducing proadipogenic signaling in caloric restriction model leads to a reduction in age-associated thymic involution (42). Obviously, much more work is needed to understand the crosstalk and interregulatory relationships between chemokines and cytokines, mesenchymal cells and adipocytes during the aging process, in particular during the thymic involution process.

Adipocytes and preadipocytes secrete a number of inflammatory cytokines including LIF, IL-1, IL-6, TNF-a among others $(43,44)$. In the thymus, we have observed an increased level of LIF, IL-6, TNF- $\alpha$ and other pro-inflammatory cytokines in the supernatant of thymus explants of 10 month-old mice as compared to the thymus explants of 2 month-old animals (our unpublished data). In addition, the expression of LIF, oncostatin M and IL-6 increases in the thymus with age $(8,45)$. Thus, it is quite reasonable to hypothesize that the production of proinflammatory cytokines by adipocytic cells could actually contribute to oxidative stress in the thymus and, consequently, to the age-associated thymic involution process, killing thymocytes and/or thymic epithelial cells and favoring the lipid accumulation in adipocytic cells. Our observations associating the increased presence of adipocytic/fat-storing mesenchymal cells and loss of thymocytes with advancing age lead to a novel conceptual point of view concerning the understanding of the process of thymic physiology in aging, where the increase in adipocytes an fat-bearing cells may 
play and active role in thymic tissue loss rather than simply increasing as a consequence of thymic loss by some other as-of-yet undescribed mechanism. Based on these findings, studies are underway to investigate the role of adipocytes and adipogenic precursors in the aging thymus physiology as well as their possible contribution to age-associated thymic involution. These studies may eventually lead to the development of strategic therapies to improve thymic integrity and thymopoiesis during aging.

\section{Acknowledgments}

We thank Dr. Alan Sher and Andre Bafica from NIAID for kindly providing the aged CCR5-deficient mice for certain studies and Prof. Dr. Radovan Borojevic for valuable discussions on this work. This work was supported by the Intramural Research Program of the National Institute on Aging, National Institutes of Health.

\section{Conflict of Interest}

The authors have declared that there is no conflict of interest with this work.

\section{References}

1. Trayhurn P, Beattie JH. Physiological role of adipose tissue: white adipose tissue as an endocrine and secretory organ. Proc. Nutr. Soc. 2001; 60: 329-39.

2. Klaus S. Adipose tissue as a regulator of energy balance. Curr. Drug Targets 2004; 5: 241-50.

3. Gregoire FM. Adipocyte Differentiation: From Fibroblast to Endocrine Cell. Exp.Biol.Med. 2001; 226: 997-1002.

4. Tilg H, Moscehn AR. Adipocytokines: mediators linking adipose tissue, inflammation and immunity. Nat. Rev. Immunol. 2006; 6: 772-83.

5. Kobayashi K. Adipokines: therapeutic targets for metabolic syndrome. Curr. Drug Targets 2005; 6: 525-29.

6. Kirkland JL, Tchkonia T, Pirtskalava T, Han J, Karagiannides I. Adipogenesis and aging: does aging make fat go MAD? Exp. Gerontol. 2002; 37: 757-67.

7. Franceschi C, Bonafe M, Valensin S, Olivieri F, De Luca M, Ottaviani E, De Benedictis G. The network and the remodeling theories of aging: historical background and new perspectives. Exp. Gerontol. 2000; 35: 879-96.

8. Mello-Coelho V, Rangel LBA, Morin PJ, Taub D. Preadipocyte-like cells in the aging thymus. In: Immunology 2004. Bologna, Italy: Medimond SRL. 2004: 279-84.

9. Weiss L. The cells and tissues of the immune systems: structure, functions, interactions. Englewood Cliffs, New Jersey: Prentice-Hall Inc. 1972.

10. Taub DD, Longo DL. Insights into thymic aging and regeneration. Immunol Rev. 2005; 205:72-93.

11. Gill J, Malin M, Sutherland J, Gray D, Hollander G, Boyd R. Thymic generation and regeneration. Immun. Rev. 2003; 195: 28-50.

12. Anderson G, Jenkinson EJ. Lymphostromal interactions in thymic development and function. Nat Rev Immunol. 2001; 1: 31-40.

13. Douek DC, McFarland RD, Keiser PH, Gage EA. Massey JM, Haynes BF, Polis MA, Haase AT, Feinberg MB, Sullivan JL,
Jamieson BD, Zack JA, Picker LJ, Koup RA. Changes in thymic function with age and during the treatment of HIV infection. Nature. 1998; 396: 690-5.

14. Ortman CL, Dittmar KA, Witte PL, Le PT. Molecular characterization of the mouse involuted thymus: aberrations in expression of transcription regulators in thymocyte and epithelial compartments. Int. Immunol. 2002; 14: 813-22.

15. Bodey B, Bodey B Jr, Siegel SE, Kaiser HE.. Involution of the mammalian thymus, one of the leading regulators of aging. In Vivo. 1997; 11: 421-40.

16. Bertho JM, Demarquay C, Moulian N, Van Der Meeren A, Berrih-Aknin S, Gourmelon P. Phenotypic and immunohistological analyses of the human adult thymus: evidence for an active thymus during adult life. Cell. Immunol. 1997; 179: 30-40.

17. Aspinall, R. Longevity and the immune response. Biogerontology. 2000; 1: 273-8.

18. Whitney LW, Becker KG, Tresser NJ, Caballero-Ramos CI, Munson PJ, Prabhu VV, Trent JM, McFarland HF, Biddison WE. Analysis of gene expression in mutiple sclerosis lesions using cDNA microarrays. Ann. Neurol. 1999; 46: 425-8.

19. Rimm DL, Camp RL, Charette LA, Costa J, Olsen DA, Reiss M. Tissue microarray: a new technology for amplification of tissue resources. Cancer J. 2001; 7: 24-31.

20. Zamarchi R, Allavena P, Borsetti A, Stievano L, Tosello V, Marcato N, Esposito G, Roni V, Paganin C, Bianchi G, Titti F, Verani $P$, Geresa G, Amadori A. Expression and functional activity of CXCR-4 and CCR-5 chemokine receptors in human thymocytes. Clin. Exp. Immunol. 2002; 127: 321-30.

21. Iwasaki M, Mukai T, Gao P, Park WR, Nakajima C, Tomura M, Fujiwara H, Hamaoka T. A critical role for IL-12 in CCR5 induction on T cell receptor-triggered mouse CD4(+) and CD8(+) T cells. Eur. J. Immunol. 2001; 31: 2411-20.

22. Hazan U, Romero IA, Cancello R, Valente S, Perrin V, Mariot V, Dumonceaux J, Gerhardt CC, Strosberg AD, Couraud PO, Pietri-Rouxel F. Human adipose cells express CD4, CXCR4, and CCR5 receptors: a new ta rget cell type for the immunodeficiency virus-1? Faseb J. 2002; 16: 1254-6.

23. Daia S, Loughlin AJ, MacQueen HA. Culture and differentiation of preadipocytes in two-dimensional and three-dimensional in vitro systems. Differentiation. 2007; 75: 360-70.

24. Russel TR, RO R. Conversion of $3 T 3$ fibroblasts into adipose cells: triggering of differentiation by prostaglandin F2alpha and 1-methyl-3-isobutyl xanthine. Proc. Natl. Acad. Sci. U.S.A. 1976; 73: 4516-20.

25. Lane MD, Tang QQ, Jiang MS. Role of the CCAAT enhancer binding proteins (C/EBPs) in adipocyte differentiation. Biochem. Biophys. Res. Commun. 1999; 266: 677-83.

26. Suniara RK, Jenkinson EJ, Owen JJT. An Essential Role for Thymic Mesenchyme in Early T Cell Development. J. Exp. Med. 2000; 191: 1051-6.

27. Ritter MA, Palmer DB. The human thymic microenvironment: new approaches to functional analysis. Semin. Immunol. 1999; 11: 13-21.

28. Boyd RL, Tucek CL, Godfrey DI, Izon DJ, Wilson TJ, Davidson NJ, Bean AG, Ladyman HM, Ritter MA, Hugo P. The thymic microenvironment. Immunol. Today. 1993; 14: 445-59.

29. Steinmann GG. Changes in the human thymus during aging. Curr. Top. Pathol. 1986; 75: 43-88.

30. Flores KG, Li J, Sempowski GD, Haynes BF, Hale LP. Analysis of the human thymic perivascular space during aging. J. Clin. Invest. 1999; 104: 1031-9.

31. Haynes BF, Market ML, Sempowski GD, Patel DD, Hale LP. The role of the thymus in immune reconstitution in aging, bone marrow transplantation and HIV infection. Ann. Rev. Immunol. 2000; 18: 529-60. 
32. Oksanen, A. Multilocular fat in thymuses of rats and mice associated with thymus involution: a light- and electron-microscope and histochemical study. J. Pathol. 1971; 105: 223-6.

33. Steinmann, GG, Klaus B, Muller-Hermelink HK. The involution of the ageing human thymic epithelium is independent of puberty. A morphometric study. Scand J. Immunol. 1985; 22: 563-75.

34. Farrington-Rock C, Crofts NJ, Doherty MJ, Ashton BA, Griffin-Jones C, Canfield AE. Chondrogenic and adipogenic potential of microvascular pericytes. Circulation 2004; 110: 2226-2232.

35. Bianco P, Riminucci M, Gronthos S, Robey PG. Bone marrow stromal stem cells: nature, biology, and potential applications. Stem Cells 2001; 19: 180-92.

36. Devine SM, Cobbs C, Jennings M, Bartholomew A, Hoffman R. Mesenchymal stem cells distribute to a wide range of tissues following systemic infusion into nonhuman primates. Blood. 2003; 101: 2999-3001.

37. Anjos-Afonso F, Siapati EK, Bonnet D. In vivo contribution of murine mesenchymal stem cells into multiple cell-types under minimal damage conditions. J. Cell Sci. 2004; 117: 5655- 64.

38. Rosen ED, Walkey CJ, Puigserver P, Spiegelman BM. Transcriptional regulation of adipogenesis. Genes and Dev. 2000; 14 : 1293-1307.

39. Mandrup S, Lane MD. Regulating adipogenesis. J. Biol. Chem. 1997; 272: 5367-70.

40. Howard JK, Lord GM, Matarese G, Vendetti S, Ghatei MA, Ritter MA, Lechler RI, Bloom SR. Leptin protects mice from starvation-induced lymphoid atrophy and increases thymic cellularity in ob/ob mice. J. Clin. Invest. 1999; 104: 1051-9.

41. Beckmann N, Gentsch C, Baumann D, Bruttel K, Vassout A, Schoeffter P, Loetscher E, Bobadilla M, Perentes E, Rudin M. Non-invasive, quantitative assessment of the anatomical phenotype of corticotropin-releasing factor-overexpressing mice by MRI. NMR Biomed. 2001; 14: 210-6.

42. Yang H, Youm YH, Dixit VD. Inhibition of Thymic Adipogenesis by Caloric Restriction Is Coupled with Reduction in Age-Related Thymic Involution. J. Immunol. 2009; 183: 3040-52.

43. Frühbeck G, Gómez-Ambrosi J, Muruzábal FJ, Burrell MA. The adipocyte: a model for integration of endocrine and metabolic signaling in energy metabolism regulation. Am. J. Physiol. Endocrinol. Metab. 2001; 280: E827-E847.

44. Rajala MW, Scherer PE. Minireview: The Adipocyte-At the Crossroads of Energy Homeostasis, Inflammation, and Atherosclerosis. Endocrinology. 2003; 144: 3765-73.

45. Sempowski GD, Hale LP, Sundy JS, Massey JM, Koup RA, Douek DC, Patel DD, Haynes BF. Leukemia inhibitory factor, oncostatin M, IL-6, and stem cell factor mRNA expression in human thymus increases with age and is associated with thymic atrophy. J. Immunol. 2000; 164: 2180-7. 